\title{
Development of standard operating procedures and quality standard of Kushta Gaodanti with HPTLC fingerprinting and hyphenated techniques
}

\author{
Mohammed Zafar*, Mohammed Abdul Rasheed Naikodi**,**, Kommu Nagaiah*** and P. V. Sunder Raju**** \\ *Govt. Nizamia Tibbi College, Charminar, Hyderabad-500002, Telangana, India \\ **Centre for Natural Products and Traditional Knowledge, CSIR-Indian Institute of Chemical Technology, Tarnaka, Hyderabad-500007, Telangana, India \\ ***National Research Institute of Unani Medicine for Skin Disorders, Opp. E.S.I. Hospital, A. G. Colony Road, Erragadda, Hyderabad 500038, Telangana, India \\ ****CSIR-National Geophysical Research Institute, Hyderabad-500 606, Telangana, India
}

\section{Article Info}

\section{Article history}

Received 1 February 2020

Revised 19 March 2020

Accepted 25 March 2020

Published online 30 June 2020

Keywords

Kushta Gaodanti

Standardization

Physico-chemical analysis

HPTLC

XRD

Metal analysis

\begin{abstract}
Kushta Goadanti is a compound Unani formulation, prescribed in Unani System of Medicine for therapeutic actions, such as Daf-e-Tap (Antipyretic), Mohallil-e-Waram (Anti-inflammatory) and therapeutic used such as In Waja-ul-Mafasil (Arthralgia), Niqras (Gout) and Irq-un-Nisa (Sciatica) has been taken up for standardization by modern hyphenated techniques, so as to ascertain its quality standards. In the present study, Kushta Gaodanti was prepared by classical methods and standardization, was carried out in the premises of Department of Ilmul Advia and approved by the Institutional Ethical Committee (NTC/A/16/101), Government Nizamia Tibbi College, Hyderabad and the modern hyphenated techniques were studied in the laboratory of CSIR-IICT (DW 0560), Tarnaka. In this study, Kushtae Gaodanti was prepared by three methods. The Kushta Gaodanti prepared was analyzed through organoleptic properties, preliminary tests and physicochemical parameters, HPTLC fingerprint study along with hyphenated techniques such as XRD studies for the metal analysis in the samples. Moreover, elements and heavy metals were also estimated in all the three samples of Kushta Gaodanti. The data and results obtained in the study are thoroughly described in the paper. The parameters such as physicochemical parameters, high performance thin layer chromatography (HPTLC) and XRD studies which are carried out, revealed as the specific identity for the drug under study and to establish as a pharmacopoeial standards. Results suggested that the drug is safe for therapeutic use and its batch-to-batch identification and determination of quality can be checked using the present study as reference standard in future.
\end{abstract}

\section{Introduction}

Kushta term refers to the finest powder form of medicinal preparations, obtained through the calcinations of metal, mineral and sometimes includes animal origin drugs. The raw drugs were processed by a special process called calcination carried in closed crucibles and also placed in pits of different sizes, bedding with the several numbers of cow dung cakes and with different intensity of heat produced through cow dung cakes. Kushta (calcined product) is easily absorbed in the human body and is highly effective in its action. Characteristics tests for properly prepared kushtajat are as there should be no metallic luster, when Kushta taken between the index finger and thumb and spread, it should be as fine as to get easily into finger lines. When a small quantity of Kushta is spread on cold and still water, it should float on the surface. The genuine Kushta prepared through the correct procedure of calcinated should not revert back to the original state.

Corresponding author: Dr. K. Nagaiah

Chief Scientist, Centre for Natural Products and Traditional Knowledge, CSIR-Indian Institute of Chemical Technology, Tarnaka, Hyderabad500007, Telangana, India

E-mail: nagaiah@iict.res.in

Tel.: +91-9440485366

Copyright (C) 2020 Ukaaz Publications. All rights reserved.

Email: ukaaz@yahoo.com; Website: www.ukaazpublications.com
WHO has emphasized the need to ensure quality control of herbal based products by using modern techniques and by applying suitable parameters and standard. To overcome certain inevitable shortfalls of the Pharmacopoeial monograph and quality control measures, there is a need of research in this direction (Pifferi et al., 1999; street et al., 2008; Shinde, 2009; Singh and Soni, 2004).

The safety, efficacy and purity of compound herbal medicines are mainly depend on the quality which directly reflects the pharmacological properties of the medicinal product. To establish the standard, only organoleptic parameters like colour, odour, taste, etc., will not be sufficient to establish the quality standard of the medicine but it requires to thoroughly study by modern hyphenated techniques to generate evidence based scientific data.

Gypsum is composed of calcium sulphate (very soft sulphate mineral). It is found in Alabaster, as a decorative purpose used in India (Kabeeruddin, 2007; Ali, 1979) and ancient Egypt. It is widely used in the manufacturing of plaster ingredients like surgical splints, casting moulds, modeling, impression plasters in dentistry. Gypsum yields water when heated and becomes white and opaque.

Kushta is a dosage form in use since ancient times in classical text of Unani literature, as it is highly effective in prevention and cure of various diseases. Unlike other formulations, preparation of 
Kushta following all classical precautions is very laborious and time consuming procedure. Preparation of Kushta entails heavy metals contamination and even those elements which are otherwise considered as toxic and not administered internally to conventional medicine. However, these materials before subjecting to calcination, is purified to get rid of impurities and toxic effects. Various detoxification and Kushta preparation methods are mentioned in classical texts, which are still in practice. Till date standardization of detoxification, standardization of heat process on scientific parameters are deficient, to convince the scientific community. Moreover, the efficacy of the drug mainly depends upon its physical and chemical properties. Therefore, the study of physicochemical, standardization (Rasheed, 2013; Rasheed et al., 2014; Rasheed et al., 2012 and Rasheed et al., 2017) is absolutely necessary in quality control of Kushtajat.

There are nearby thirty chemical elements that have their vital importance in various biochemical and physiological mechanisms in living organisms and considered as essential elements of life. Heavy metals also have great impact on human health and even those considered as essential can be toxic, if they are present in excess. Generally, humans are exposed to these metals by ingestion and inhalation. The term 'heavy metals' refer to any metallic elements that has a relatively high density and are causing toxic effects or poisonous even at low concentration. "Heavy metals" in general applies to the group of metals and metalloids with atomic density greater than $4 \mathrm{gm} / \mathrm{cm}$, or 5 times or more, greater than water. Most common heavy metals are Lead ( $\mathrm{Pb})$, Arsenic (As), Cadmium (Cd), Nickel (Ni), Cobalt (Co), Zinc (Zn), Chromium $(\mathrm{Cr})$, Iron $(\mathrm{Fe})$, Silver $(\mathrm{Ag})$ and the platinum groups (Dubey et al., 2008).

Therefore, in the present study, an attempt has also been made to estimate the heavy metals and other important elements present in the three samples of Kushta-e-Gaodanti.

However, the traces or little amount of heavy metals are basically present in some of the simple and compound Kushta formulations of Unani medicine which are being used for centuries. Unani compound formulation like Kushta, contain toxic elements/metals. That is used as detoxified after various purification processes like soaking, quenching, trituration, incineration, etc. Classical Unani texts have elucidated several detoxification processes for this purpose by various methods like using herbal pulps, extracts, etc. Hence, metals in the finished products may not possess toxicity. Though, such purification processes have been carried out by the
Unani physicians, in accordance with described methodology, but these methods should be validated on experimental basis to the claims especially in reference to study the change and reduction of the toxicological symptoms due to their toxicity.

A polyherbal formulation, Kushta Goadanti is a popular drug which is widely used as an antipyretic, anti-inflammatory medicine taken for the present study is a Unani compound formulation mentioned in National formulary of Unani medicine of India, Part-V (Anonymous, 2008). The main ingredient of the formulation is Hartal Gaodanti or Gaudanti which means Gypsum or hydrated calcium sulphate $\left(\mathrm{CaSO}_{4} \cdot 2 \mathrm{H}_{2} \mathrm{O}\right)$. The drug is prescribed in Unani system of medicine for actions such as Daf-e-Tap (Antipyretic), Mohallil-e-waram (Anti-inflammatory) and therapeutic used such as In Waja Mafasil (Arthralgia) (Zillurahman, 1985); Niqras (Gout) and Irq-un-Nisa (Sciatica). It is used in multiple systemic disorders like Muhallil-e-waram (inflammation), Hummiyath (Pyrexia), Falij (Haemiplegia), Waj-ul-mafasil (Rheumatism) (Tariq et al., 2013; Khan, 2012; Anonymous, 2009a; Anonymous, 2004; Anonymous, 2007; Gani, 1998; Kulkarni, 1991; Nadkarni, 1976; Ibn Baitar, 1999). A various classical process of detoxification and preparation of Kushta gaodanti mentioned but to establish a pharmacopoeial reference standard, an attempt had been made out in the present study. The study is aimed to evaluate the differences, if any in the various samples of Kushta Gaodanti prepared by different methods of detoxification.

\section{Materials and Methods}

\section{Collection of material}

Gaodanti, Gheegawar (Aloe barbadensis Mill.), Asgand (Withania somnifera (L.) Dunal) (Figure 1) was procured from the local herbal drug supplier, authenticated and identified before using. It was cleaned thoroughly to remove any foreign matter present on it.

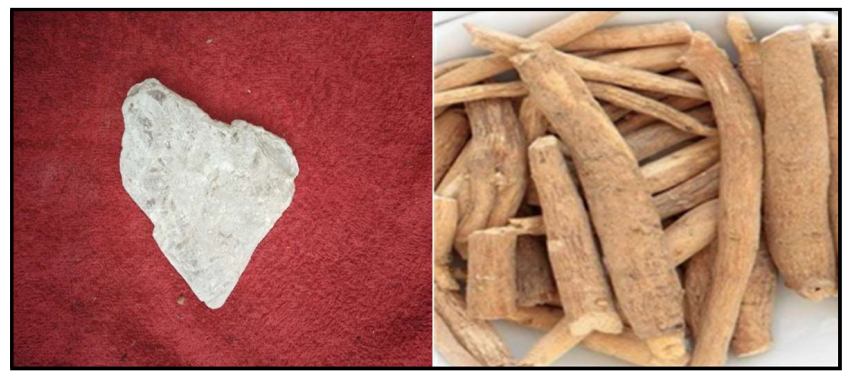

Figure 1: Raw drugs-Gaodanti and Asgand.

Preparation of the formulation: NFUM. V, p 54-(Anonymous, 2008)

It is prepared according to the composition of the formulation as follows:

\begin{tabular}{|l|l|l|l|}
\hline \multirow{2}{*}{ Formula 1: KGF1 } & Gaodanti & Calcium sulphate & $100 \mathrm{~g}$. \\
\cline { 2 - 4 } & Gheegawar & Pulp of Aloe barbadensis Mill. & $100 \mathrm{~g}$. \\
\hline \multirow{2}{*}{ Formula 2: KGF2 } & Gaodanti & Calcium sulphate & $100 \mathrm{~g}$. \\
\cline { 2 - 4 } & Joshanda-e-Asgand & Decoction of roots of Withania somnifera (L.) Dunal & $100 \mathrm{ml}$ \\
\hline \multirow{3}{*}{ Formula 3: KGF3 } & Gaodanti & Calcium sulphate & $100 \mathrm{~g}$. \\
\cline { 2 - 4 } & Sufoof-e-Asgand & Powder of roots of Withania somnifera (L.) Dunal & $100 \mathrm{~g}$. \\
\cline { 2 - 4 } & Gheegawar & Pulp of Aloe barbadensis Mill. & $100 \mathrm{~g}$. \\
\hline
\end{tabular}


The present study, Kushta Gaodanti was prepared by classical methods and standardization was carried out in the premises of Department of Ilmul Advia and approved by the Institutional Ethical Committee (NTC/A/16/101), Govt. Nizamia Tibbi College, Hyderabad, India and the modern hyphenated techniques were studied in the laboratory of CSIR-IICT (DW 0560), Tarnaka, Hyderabad, India. In this study, Kushtae Gaodanti was prepared by three methods are as given below:

Formula 1: KGF1 as per Qarabadeen-e-Majeedi (Anonymous, 1986)

The ingredients of Khusta Goadanti as described above are taken as described in the pharmacopoeia and ingredients are cleaned and made free from any foreign materials. Gaodanti was cleaned with hot water dried and $100 \mathrm{~g}$ of purified Gaodanti was powdered using mortar and pestle. Add $100 \mathrm{ml}$ pulp of gheegawar and grinded in mortar for $4 \mathrm{~h}$ and made into paste. The obtained paste made into pellets (Anonymous, 1986) (Figure 2) and dried at room temperature for one day. A pit was dug about one and half feet and pellets were place between the cowdungs and covered with clay (Gil-e-Hikmat) and subjected to ignition to dry completely. Next day morning, the cowdungs were removed and the pellets burned out where collected powdered separately in mortal and pistle and stored.

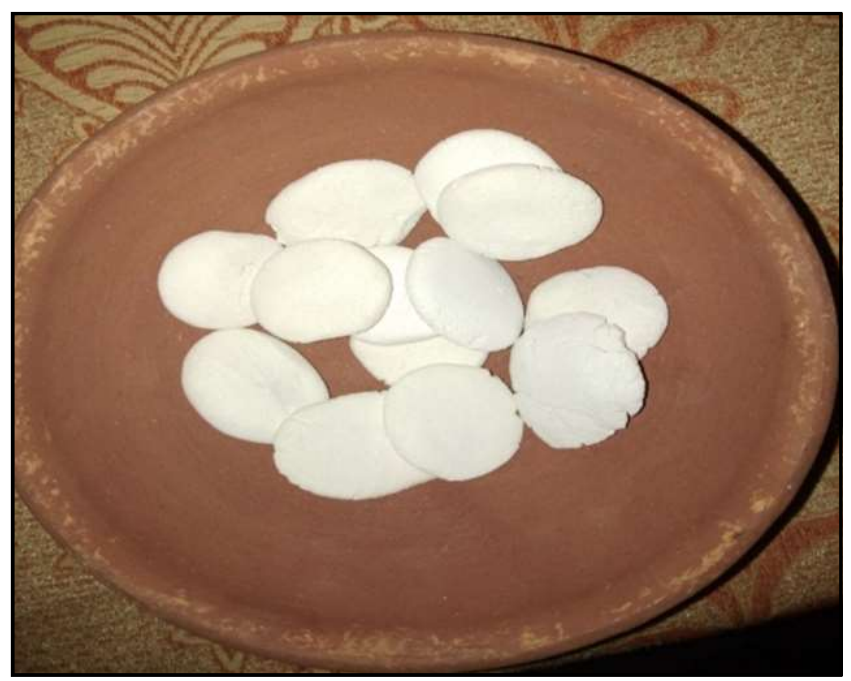

Figure 2: Pelletes preparation for Khusta preparation.

Formula 2: KGF2 as per National Formulary of Unani Medicine (Anonymous, 2006).

Roots of Withania somnifera (Ashwagandha) was taken of about $100 \mathrm{~g}$ and soaked in $200 \mathrm{ml}$ of warm water till night. Next day, boil the mixture and decoction was collected and filtered. Gaodanti was cleaned with hot water dried and $100 \mathrm{~g}$ of purified Gaodanti was powdered using mortar and pestle. The filtered Asgand decoction was added to Gaodanti powdered and triturated till it turns into paste. The obtained paste made into pellets and dried at room temperature for one day. After this, the same procedure was followed for the pellets as mention in formula 1 .

Formula 3: KGF3 as given in The Text Book of Unani Pharmacy. (Parwaiz and Parveen, 2012) Take Gaodanti and Asgand roots of pharmacopoeial quality and clean the ingredients. Gaodanti was cleaned with hot water dried and $100 \mathrm{~g}$ of purified Gaodanti was powdered using mortar and pestle. In an earthen pot, the Gaodanti powder was placed in such a way that the Gaodanti powder was between the layers of Asgand powder. Then add $100 \mathrm{ml}$ of pulp of gheegawar to it and seal the earthen pot with clay (Gil-e-hikmat). A pit fill with $20 \mathrm{~kg}$ cowdung cakes and earthen pot was kept over it and ignited. Next day morning, the inside powdered material was removed finely powdered using mortar and pistle and stored in air tight closed glass container.

\section{Experiment}

The Kushta Gaodanti prepared in three different methods: i. Kushta Gaodanti grounded in gheegawar pulp (KGF1), ii. Kushta Gaodantiprepared in decoction of asgand (KGF2), and iii. Kushta Gaodanti prepared with asgand powder and gheegawar pulp (KGF3) and all the three samples were evaluated for differences in the organoleptic, physicochemical, HPTLC, XRD properties. Physicochemical parameters such as particle size, total ash, acid insoluble ash, $\mathrm{pH}$, bulk density, loss of weight on drying at $105{ }^{\circ} \mathrm{C}$, etc., were also carried out.

Kushta Gaodanti has different functions, depending upon the method of preparation. So, far the physicochemical characteristics of Kushta Gaodanti have not been previously evaluated on scientific parameters. Therefore, the present study was aimed to prepare Kushta Gaodanti by detoxifying Gaodanti in two different media and one in both media to observe and document the changes, occurring after calcinations and inscribe the physicochemical properties of the finished product. In the present study, preparation process of Kushta Gaodanti in various texts of Kushta sazi where the purification process is same in all texts triturating with different plant material extracts. Many texts mention multiple uses of Kushta Gaodanti prepared by Aloe vera juice and asgand decoction, and in both. NFUM also mentioned scientifically. Hence, all the three methods were taken as standard and try to evaluate the changes, if any.

In order to standardize and to lay down the standard operating procedures (SOP's) and pharmacopoeial standards, the formulation was prepared in three different methods at laboratory scale. It was subjected to analysis for organoleptic parameters, physicochemical parameters, TLC, high performance thin layer chromatographic (HPTLC) studies (Anonymous, 2009b; Naikodi, et al., 2011). The present paper describes the salient features of preparation, organoleptic parameters, phytochemical screening, safety evaluation studies and high performance thin layer chromatographic studies for the drug.

Organoleptic characters: Prepared Kushta was evaluated for colour, odour, taste and luster characteristics.

\section{Preliminary test}

i. Floating test: Small quantity of Kushta was sprinkled on water and observed if it floats on the surface or not.

ii. Fineness test: Fineness and smoothness were recorded by rubbing a small quantity of Kushta between the index finger and thumb and noted whether it deposits into crease and lines on ventral aspects of fingers.

iii. Loss of metallic lustre: Kushta was examined for metallic luster with naked eye in sun light. 
iv. Wall stick test: Kushta was also examined by throwing on the wall to check whether it stick to the wall or not.

v. Bulk density and tapped density: 10 g of weighed Kushta was carefully added to the cylinder with the aid of a funnel. The initial volume was noted and the sample was then tapped until no further reduction in volume was observed. The bulk and tapped densities were calculated by the formula.

vi. Loss of weight on drying at $105{ }^{\circ} \mathrm{C}$ : $200 \mathrm{mg}$ of Kushta was spread uniformly in petridish and was heated at $105^{\circ} \mathrm{C}$ then cooled in a desiccator and weighed. The process was repeated till two consecutive weights were constant. The per cent loss in weight was calculated.

vii. Determination of $\mathrm{pH}$ in $1 \%$ solution: The $\mathrm{pH}$ value of $1 \%$ solution in accurately weighed $1 \mathrm{gm}$ of Kushta was dissolved in accurately measured $100 \mathrm{ml}$ of distilled water and filtered with whatman filter paper. $\mathrm{pH}$ was measured using a digital $\mathrm{pH}$ meter.

viii. Total ash: 2 gm of Kushta was incinerated in a silica crucible at a temperature not exceeding $450{ }^{\circ} \mathrm{C}$. The crucible was then cooled and weighed and the percentage of total ash was calculated.

ix. Acid insoluble ash: The ash was boiled with $25 \mathrm{ml}$ of dilute hydrochloric acid for $5 \mathrm{~min}$. The insoluble matter or ash which was collected or left behind on filter paper (ash less) was washed with hot water and then subjected to ignition at a temperature not exceeding $450{ }^{\circ} \mathrm{C}$ and weighed after cooling to room temperature. The percentage of acid insoluble ash was calculated.

x. Water insoluble and water soluble ash: The ash was boiled with $25 \mathrm{ml}$ of distilled water for $5 \mathrm{~min}$. The insoluble matter was collected on an ash less filter paper, washed with hot water and ignited. The weight or amount of insoluble ash obtained was subtracted from the weight of the total ash obtained, which provides the resultant weight of the water soluble ash.

HPTLC analysis

Preparation of chloroform extract for HPTLC analysis

Five grams fine powder of KGF1, KGF2, KGF3 was placed in a conical flask and $100 \mathrm{ml}$ of chloroform was added and kept on shaker for $8 \mathrm{~h}$. Flasks were removed and the contents were filtered through Whatman No. 41 filter paper and evaporated the resultant solution to become $20 \mathrm{ml}$. Thus, the solution so obtained was used for HPTLC.

\section{Development and determination of the solvent system}

The sample extracts applied was about $10 \mu 1$ and the mobile phase system was used as $100 \%$ hexane. The sample was spotted with the help of automatic TLC applicator on the precoated aluminium sheets of silica gel $60 \mathrm{~F}_{254}$ (Merck) and developed in the TLC chamber to develop the TLC plate.

\section{Development of HPTLC technique}

The TLC plate after developing was removed and dried completely and detected under with the suitable detection system, Ultraviolet Cabinet system for detection of spots at $\lambda=254 \mathrm{~nm}$ as shown in the
Figure 3. Further, it was scanned with the densitometer under the UV range of $\lambda=254 \mathrm{~nm}$ as shown in the Figure 4.

Metal analysis

In this study, elemental analysis was carried out by Energy Dispersive X-Ray Fluorescence (CSIR-NGRI), XRD Analysis (CSIRNGRI), FTIR (CSIR IICT), Thin Layer Chromatography (CSIR IICT).

\section{Energy dispersive X-ray fluorescence (EDXRF)}

Non-destructive studies were carried out at the Council of Scientific and Industrial Research and National Geophysical Research Institute (CSIR-NGRI) facility. The EDXRF spectrometer (Epsilon 5: PAN analytica, Netherlands make) used in the present studyequipped with a ScW anode X-ray tube with the goal of increased sensitivity for lighter as well as heavier elements. The instrument has a series of user selectable secondary targets and is equipped with a liquid-nitrogen-cooled Ge solid-state high-resolution detector with a $\mathrm{Be}(8 \mathrm{~lm})$ window. A 3-D design (or Cartesian geometry) was adopted for the instrument to eliminate the X-ray tube spectrum by polarization. Consequently, the background can be an order of magnitude lower than the traditional 2-Doptics, resulting in much lower detection limits. The EDXRF used in the present study is equipped with a $100 \mathrm{kV} \mathrm{Sc} / \mathrm{W}$ tube, even heavy rare earth elements (from $\mathrm{Eu}$ to $\mathrm{Lu}$ ) can be analyzed using the more sensitive " $\mathrm{K}$ " lines and, hence the instrument is less susceptible to spectral overlapping with the $\mathrm{K}$ lines of lighter elements. The samples were analyzed using the pressed powder pellets in $40 \mathrm{~mm}$ dia and were measured using the $100 \mathrm{kv}$ voltage to excite all the $\mathrm{k}$ alpha $\mathrm{x}$-ray lines (Mohammad et al., 2016; Raju et al., 2016; Raju, 2019).

\section{Results}

The Kushta Gaodanti prepared by three different samples were analyzed for organoleptic properties, preliminary tests and physicochemical study. Moreover, elements and heavy metals were also estimated in all the three samples of Kushta Gaodanti.

Organoleptic properties: Appearance of all the three samples KGF1, KGF2 and KGF3 was found to be lusterless. Colour was observed to be dark grey in KGF1 and greyish white in KGF2 and KGF3. Smell KGF1, KGF2 and KGF3 was found odourless, and all three samples KGF1, KGF2 and KGF3 found to be salty in taste. Form of KGF1, KGF2 and KGF3 was found as fine powder.

Physicochemical parameters were analyzed in Kushta Gaodanti prepared by classical methods and the data presented in Table 1.

pH value: $\mathrm{pH}$ value of all the three Kushta is acidic. It is mentioned that most of the Kushtajat are alkaline and some are weakly acidic. $\mathrm{pH}$ of drug is also an important parameter to assess the quality of drug. The drugs that are weak acids, would be better absorbed from the stomach then from the upper intestine. Bulk density, total ash, loss of weight on drying at $105{ }^{\circ} \mathrm{C}$, etc., also authenticates the recommendation of Unani physicians to preserve the Kushta properties and establishing standards. 
Table 1: Physicochemical parameters of Kushta Gaodanti

\begin{tabular}{|l|l|l|l|l|}
\hline S.no & Parameter & Sample 1 KGF1 & Sample 2 KGF2 & Sample 3 KGF3 \\
\hline 1. & Appearance & lusterless & lusterless & lusterless \\
greyish white \\
greyish white & odourless \\
3. & Colour & Sark grey & odourless & $<10 \mu \mathrm{m}$ \\
4. & pH & odourless & acidic & 0.87 \\
5. & Particle Size & $<10 \mu \mathrm{m}$ & $<10 \mu \mathrm{m}$ & 95.2413 \\
6. & Bulk density & 0.95 & 0.97 & 73.5726 \\
7. & Total Ash $(\% \mathrm{w} / \mathrm{w})$ & 99.8675 & 0.4901 \\
8. & Acid Insoluble Ash $(\% \mathrm{w} / \mathrm{w})$ & 73.2684 & 4.23 \\
9. & Loss of Wt. on drying at $105{ }^{\circ} \mathrm{C}(\% \mathrm{w} / \mathrm{w})$ & 79.0452 & 0.4956 & Sinks in water \\
10. & pH Value at $1 \%$ aq. solution & 4.01 & 4.17 & partially positive \\
11. & Distilled water test & Sinks in water & pinks in water & partially positive \\
12. & Still water test & positive & partially positive & positive \\
13. & Wall stick test & positive & positive & positive \\
14. & Floating test & positive & positive & \\
15. & smoothness & positive & & \\
\hline
\end{tabular}

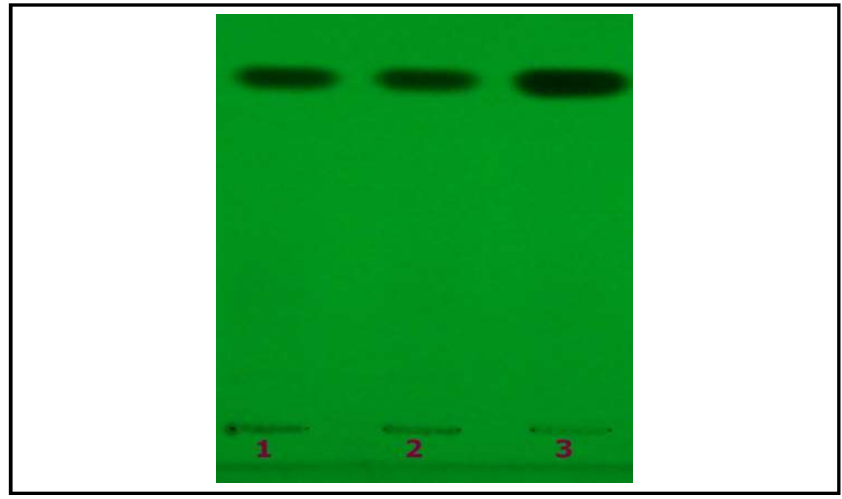

Figure 3: TLC plate of chloroform extract of Kushta Gaodanti. Three different samples developed with $100 \%$ hexane and detection at UV $\lambda=254 \mathrm{~nm}$ wavelength (Track 1: KGF1; Track 2: KGF2; Track 3: KGF3).

\section{HPTLC analysis}

HPTLC fingerprint of chloroform extract of Kushta Gaodanti prepared by three different samples, were carried out and TLC plate was developed with $100 \%$ hexane as mobile phase (Figure 3).

\section{XRD-analysis}

The non-destructive analytical technique using EDXRF is carried out using an in-built "Auto quant" program developed by (M/s Panlytical $^{\mathrm{R}}$ ) using matrix match standards around $100 \mathrm{wt} \%$ element concentration of elements measured. The elemental abundance on an average in three samples consists of Calcium (Ca) $\sim 12.33 \mathrm{wt} \%$, Zinc,(Zn) $17.66 \mathrm{wt} \%$ with only exception to KNG-3 sample consisting of heavy metals like Arsenic with (As) 1 ppm and Lead $(\mathrm{Pb})$ around $14 \mathrm{ppm}$. The $\mathrm{SO}_{3}$ is a chemical compound of sulphur and trioxide, sulfite with sulphur and oxygen with 2-charge. On average, $\mathrm{SO}_{3}$ present around $\sim 62.33 \mathrm{wt} \%$. To ascertain the enrichment of the elemental abundance's measured by EDXRF, we also corroborated the studies using XRD to understand the mineral species responsible (Figures 5-7).

\section{Discussion}

Preliminary tests: The Khusta Gaodanti samples prepared were analyzed for metallic luster and found to be negative in all the three samples KGF1, KGF2 and KGF3. The prepared Kushta was lusterless, which was in accordance to good quality of Kushta mentioned by

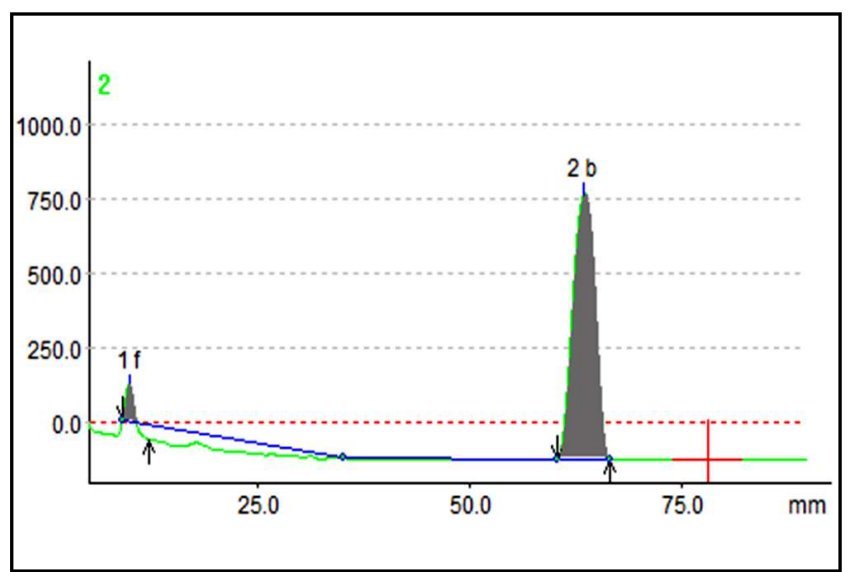

Figure 4: Densitogram of chloroform extract of Kushta Gaodanti at UV $\lambda=254 \mathrm{~nm}$.

Unani scholars. It is mentioned that the processing by which kushtajat is prepared leads to loss of luster. Finger thumb test was found to be positive in all the three samples KGF1, KGF2 and KGF3. Fineness test: The fineness and smoothness of Kushta indicates that the Kushta as deposited into crease and lines on ventral aspects of fingers, which confirms its smoothness and fineness, showing the particle size of Kushta was very small and also found below 10 $\mathrm{nm}$ with particle size analyzer. Stillwater test and Wall stick test was found to be positive in KGF1, KGF2 and partially positive in KGF3. Floating test was found to be positive in KGF1, KGF2, and in KGF3. Floating test findings was consistent with classical literature that an ideal kushta floats over the surface of water as floating on the surface of liquid. The Kushta particles though denser than water its size is very small and unable to overcome the force of surface tension of water, thus it floats on the surface of the water (Table 1).

Physicochemical parameters were analyzed in Kushta Gaodanti prepared by classical methods results are described as the particle size was determined using a laser scattering particle size analyzer (Malvern ZetaSizer ZEN3600, UK). The particle size was found to be less than $10 \mathrm{~nm}$ in all KGF1, KGF2, and KGF3. pH of $1 \%$ aqueous solution was found to be 4.01 in KGF1, 4.17 in KGF2, and 4.23 in KGF3. Bulk density: The mean value of bulk density of all the three samples was found to be 0.95 in KGF1, 0.97 in KGF2, and 0.87 in KGF3. Total ash: The mean value of total ash of all the three samples 
found to be $98.9924 \% \mathrm{w} / \mathrm{w}$ in $\mathrm{KGF} 1,99.8675 \% \mathrm{w} / \mathrm{w}$ in $\mathrm{KGF} 2$, and $95.2413 \% \mathrm{w} / \mathrm{w}$ in KGF3. The mean percentage of loss of weight on drying at $105^{\circ} \mathrm{C}$ was found to be $0.48122 \% \mathrm{w} / \mathrm{w}$ in KGF $1,0.4956 \%$ $\mathrm{w} / \mathrm{w}$ in $\mathrm{KGF} 2$ and $0.4901 \% \mathrm{w} / \mathrm{w}$ in KGF3. Acid insoluble ash was found to be $79.0452 \% \mathrm{w} / \mathrm{w}$ in KGF1, 73.2684\% w/w in KGF2 and $73.5726 \% \mathrm{w} / \mathrm{w}$ in KGF3. (Table 1)

\section{HPTLC analysis}

HPTLC fingerprint of chloroform extract of Kushta Gaodanti prepared by three different samples were carried out and TLC plate was developed with $100 \%$ hexane as mobile phase (Figure 3 ) and detected using the UV visible chamber which clearly showed a spot in UV $254 \mathrm{~nm}$ in the densitogram (Figure 4 and Table 2). The corresponding Rf value for the spot obtained in the TLC plate for the Kushta Gaodanti and the spot detected under UV wavelength of $\lambda=254 \mathrm{~nm}$ at Rf value 0.90 (black). This helps in identification of Khusta under the same experimental conditions with single spot at Rf value of 0.90

Table 2: Peak list of chloroform extract of Kushta Gaodanti at UV $\lambda=254 \mathrm{~nm}$

\begin{tabular}{|c|c|c|c|c|c|}
\hline Peak no & Y-Pos & \multicolumn{1}{c|}{ Area } & Area \% & Height & Rf value \\
\hline 1 & 9.8 & 118.01 & 4.24 & 122.68 & 0.01 \\
2 & 63.6 & 2667.17 & 95.76 & 886.68 & 0.90 \\
\hline
\end{tabular}

XRD-analysis

In the Kushta Gaodanti sample, i.e., KNG -1, the calcium enrichment is due to calcium sulphate identified at 2 theta 41 degree and a sharp peak of $2 c$ theta at 26 degrees indicative the presence of lead thallium. In KNG 2, the $\mathrm{Nd}_{3} \mathrm{NiGaS}_{7}$ (Nickel Gallium Neodymium Sulfide) is identified at 25.5 2theta angle, minor peaks of lead $(\mathrm{Pb}), \mathrm{ZrO}$, TiO0.577WO0.316 (Titanium-tungsten Zirconium), $\mathrm{V}_{2} \mathrm{Mn}_{2} \mathrm{O}_{7}$ (Vanadium, Manganese Oxide $\mathrm{Ti}_{2} \mathrm{Cu}_{3}$, etc., are also picked using Bruker TOPAS program. In KNG-3, sharp peaks of calcium contents is due to presence of anhydrite $\left(\mathrm{CaSO}_{4}\right)$ and Oldhamite, i.e., a $\mathrm{CaS}$ form. (Coupled TwoTheta/Theta Figures 5-7)

\section{Metal analysis}

Calcium analysis was carried out in KGF1, KGF2 and KGF3. The result was found to be $36.46 \%, 36.93 \%$ and $38.29 \%$, respectively. The elemental percentage was found to be similar in all the three samples, but slightly higher in third sample, i.e., KGF3.

Iron and magnesium analysis were also done in all the said three samples. The presence of iron was found to be $0.08 \%, 0.07 \%$ and $0.10 \%$, while the magnesium presence was found to be $0.04 \%$, $0.08 \%$ and $0.20 \%$. Here, the different values amongst the various preparation methods of iron and magnesium are insignificant. However, the difference in third sample may be due to the use of Asgand and Gheekwar in its whole form. Thus, the results of Kushtae Gaodanti in third method of preparation suggest high yield in comparison to other methods of preparation.

\section{Heavy metal analysis}

The analysis of heavy metals as per the methods described in WHO guidelines. Anonymous (1998) is carried out in the above mentioned three samples of Kushtae Gaodanti. The results of heavy metals determination were within the permissible limits as given in Table 3 . The value of cadmium, mercury lead and arsenic was below detectable amount in KGF1 and KGF2. Whereas in KGF3, the arsenic was found to be $1 \mathrm{ppm}$ which is a permissible limit. The lead $(\mathrm{Pb})$ value was found to be $14 \mathrm{ppm}$ which is exceeding the permissible limit (10 ppm). Here, the probable cause of higher values in KGF3 may be due to the preparation method of third sample adopted where the raw asgand powder and gheekwar were used in their whole form avoiding pellatization process. Due to which, the heat transformation could have not been equally distributed. XRDanalysis showed the presence of calcium and silicate in all the three samples of Khusta-e-Gaodanti, prepared by classical method. Traces of copper $(\mathrm{Cu})$, Zinc $(\mathrm{Zn})$, Chlorine $(\mathrm{Cl})$ are present. All the above metals are useful to human body. But heavy metals like Arsenic (As), Strontium ( $\mathrm{Sr}$ ) and lead $(\mathrm{Pb})$ are also present in the third sample of khusta-e-Gaodanti.

Table 3: Heavy metals and elemental analysis by EDXRF in Kushta gaodanti

\begin{tabular}{|l|l|l|r|r|r|}
\hline S. No. & Result & Units & KNG-1 & KNG-2 & KNG-3 \\
\hline 1. & $\mathrm{CaO}$ & $\%$ & 36.46 & 36.93 & 38.29 \\
2. & $\mathrm{~K}_{2} \mathrm{O}$ & $\%$ & 0.04 & 0.08 & 0.20 \\
3. & $\mathrm{Fe}_{2} \mathrm{O}_{3}$ & $\%$ & 0.08 & 0.07 & 0.10 \\
4. & $\mathrm{SiO}_{2}$ & $\%$ & 0.03 & 0.00 & 0.00 \\
5. & $\mathrm{SO}_{3}$ & $\%$ & 63.24 & 62.78 & 61.14 \\
6. & $\mathrm{Cr}_{2} \mathrm{O}_{3}$ & $\%$ & 0.00 & 0.00 & 0.10 \\
7. & $\mathrm{Cl}^{2}$ & $\%$ & 0.11 & 0.09 & 0.15 \\
8. & $\mathrm{Cu}$ & ppm & 12.00 & 15.00 & 10.00 \\
9. & $\mathrm{Zn}$ & ppm & 13.00 & 18.00 & 22.00 \\
10. & $\mathrm{Sr}$ & ppm & 295.00 & 333.00 & 282.00 \\
11. & $\mathrm{As}$ & ppm & 0.00 & 0.00 & 1.00 \\
12. & $\mathrm{Hg}$ & ppm & 0.00 & 0.00 & 0.00 \\
13. & $\mathrm{Cd}$ & ppm & 0.00 & 0.00 & 0.00 \\
14. & $\mathrm{~Pb}$ & ppm & 0.00 & 0.00 & 10.00 \\
\hline
\end{tabular}

Physicochemical parameters were analyzed in Kushta Gaodanti prepared $b$ Gaodanti prepared in decoction of Asgand also have no traces of arsenic and lead.

Gaodanti prepared in both Aloe vera and asgand powder has traces of arsenic and lead as shown in Table 3. Hence, this formula is not advisable for treatment as it contains heavy metals.

Though strontium is present in high amount (280-333 ppm), as strontium is absorbed by the body in similar manner to that of calcium, is not hazardous to health.

As no standard physicochemical profile of Kushtae Gaoanti is reported till date, the current data may be considered as standard for future studies. The analytical result showed the presence of calcium and copper in KGF1, KGF2 and KGF3, whereas traces of arsenic and lead are present in KGF3.

The studies done by Dubey et al. (2008); Takkar et al. (2017) and Khan et al. (2012) conform the calcium presence in Kushtae Gaodanti to $29.32 \%, 42.30 \%$ and $29.30 \%$, respectively. The study done by Central Council for Research in Unani Medicine, New Delhi, India also suggests the presence of calcium in Kushtae Gaodanti with $32-38 \mathrm{mg} / \mathrm{gm}$ amount being closer to reported results.

Hence, the present study was aimed to prepare Kushtae Gaodanti by triturating in two different media with different weights of cow dung cakes (KGF1 and KGF2), one method prepared by without trituration and pellatization (KGF3). The data of the present study suggest that the physcicochemical characteristics of KGF1 and KGF2 were similar, whereas KGF3 differs in heavy metals like arsenic and lead values. Hence, the study validates trituration and pellatization plays an important role in the preparation of Kushtajat. 

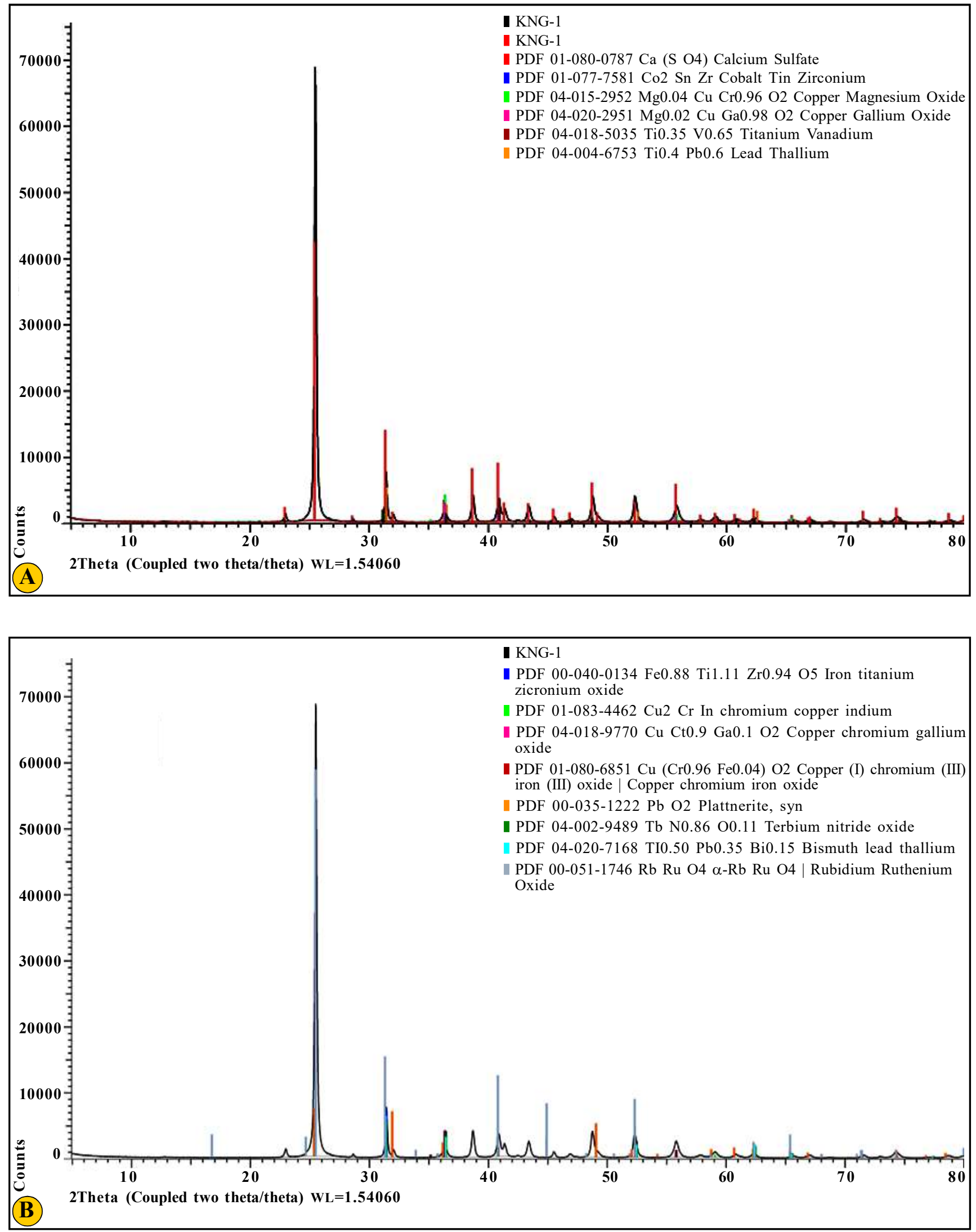

Figure 5: 2Theta_(Coupled two theta/theta) for KGF1(A-B). 


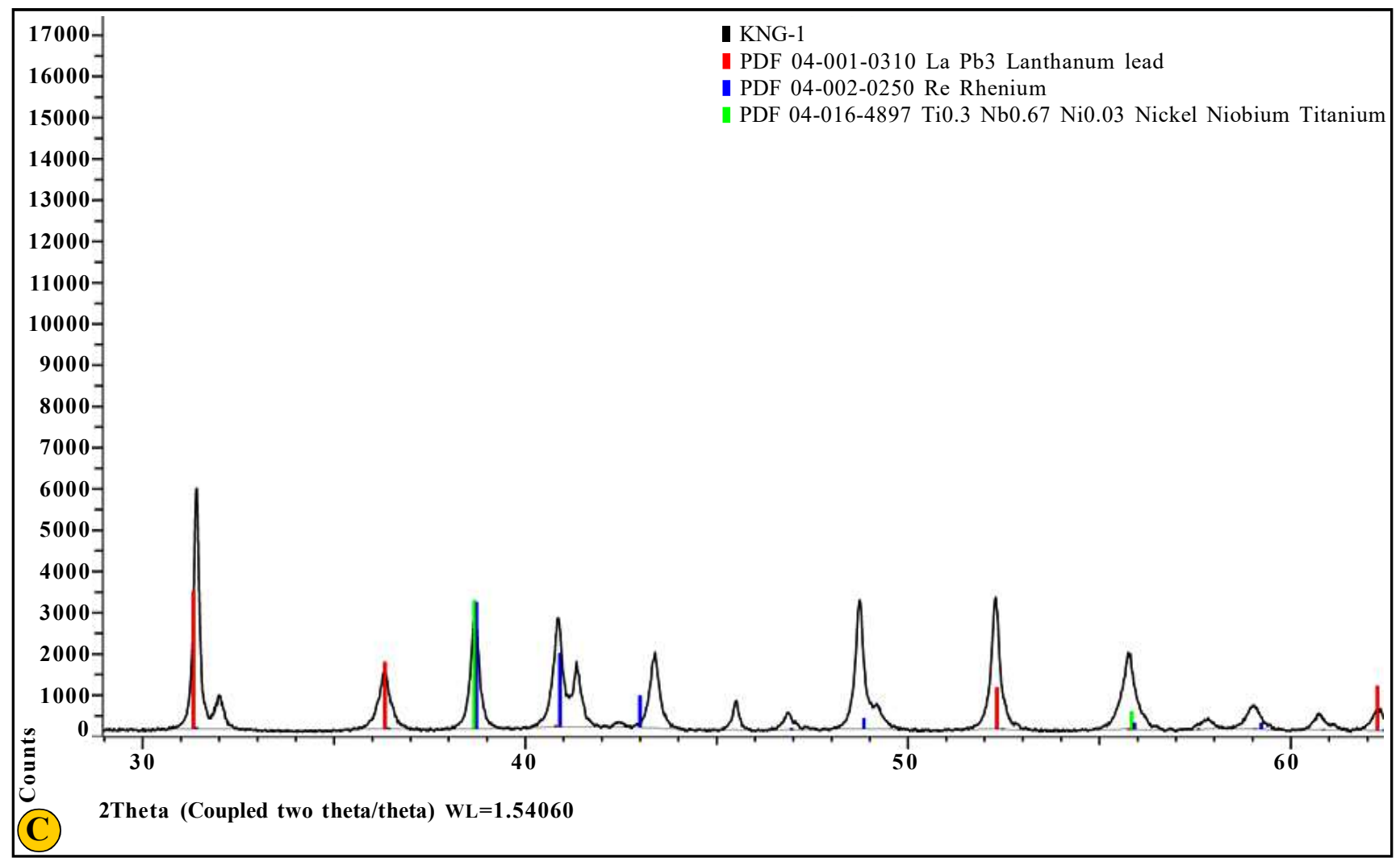

Figure 5: 2Theta_(Coupled two theta/theta) for KGF1(C).

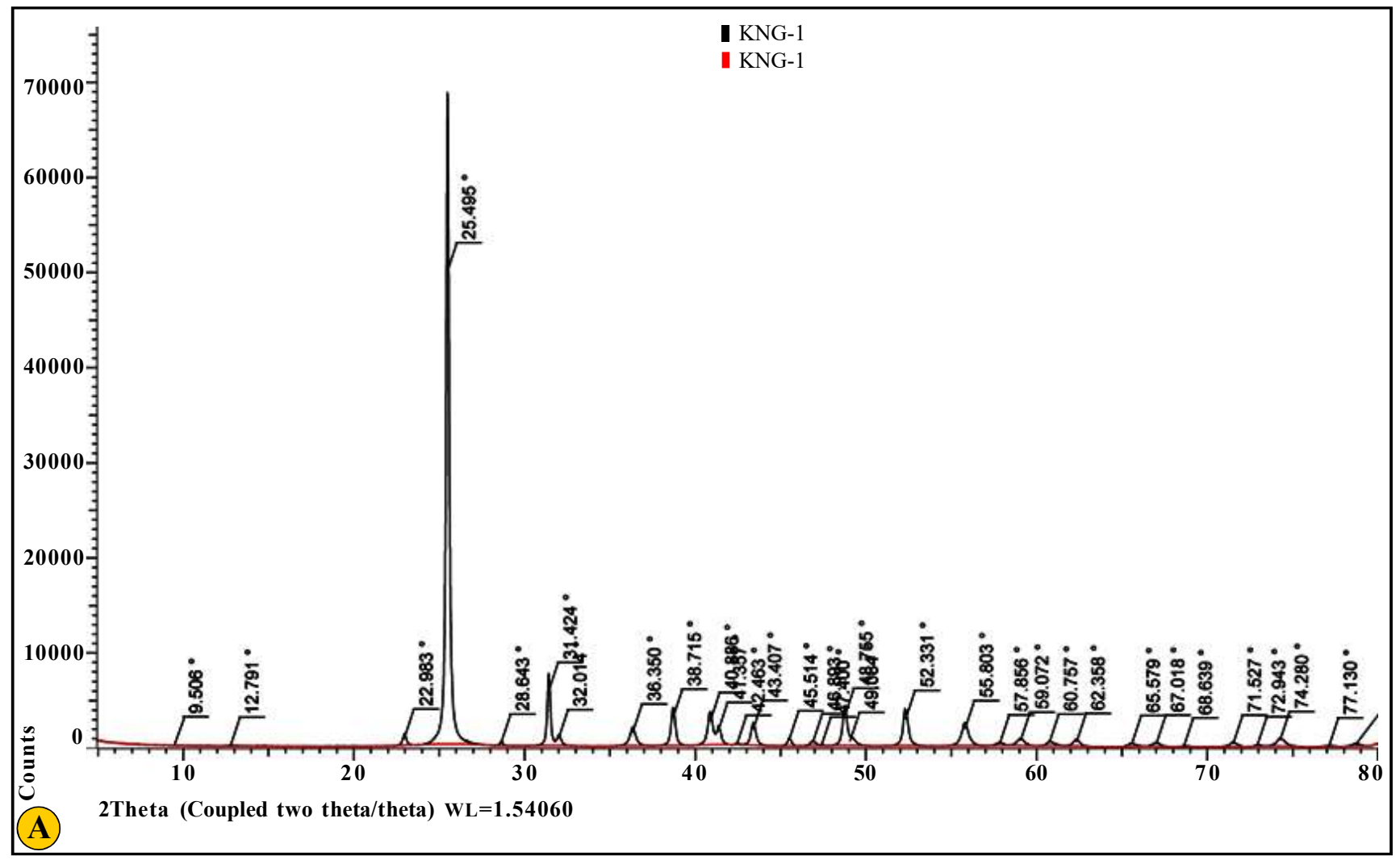

Figure 6: 2Theta_(Coupled two theta/theta) for KGF 1\&2 (A). 

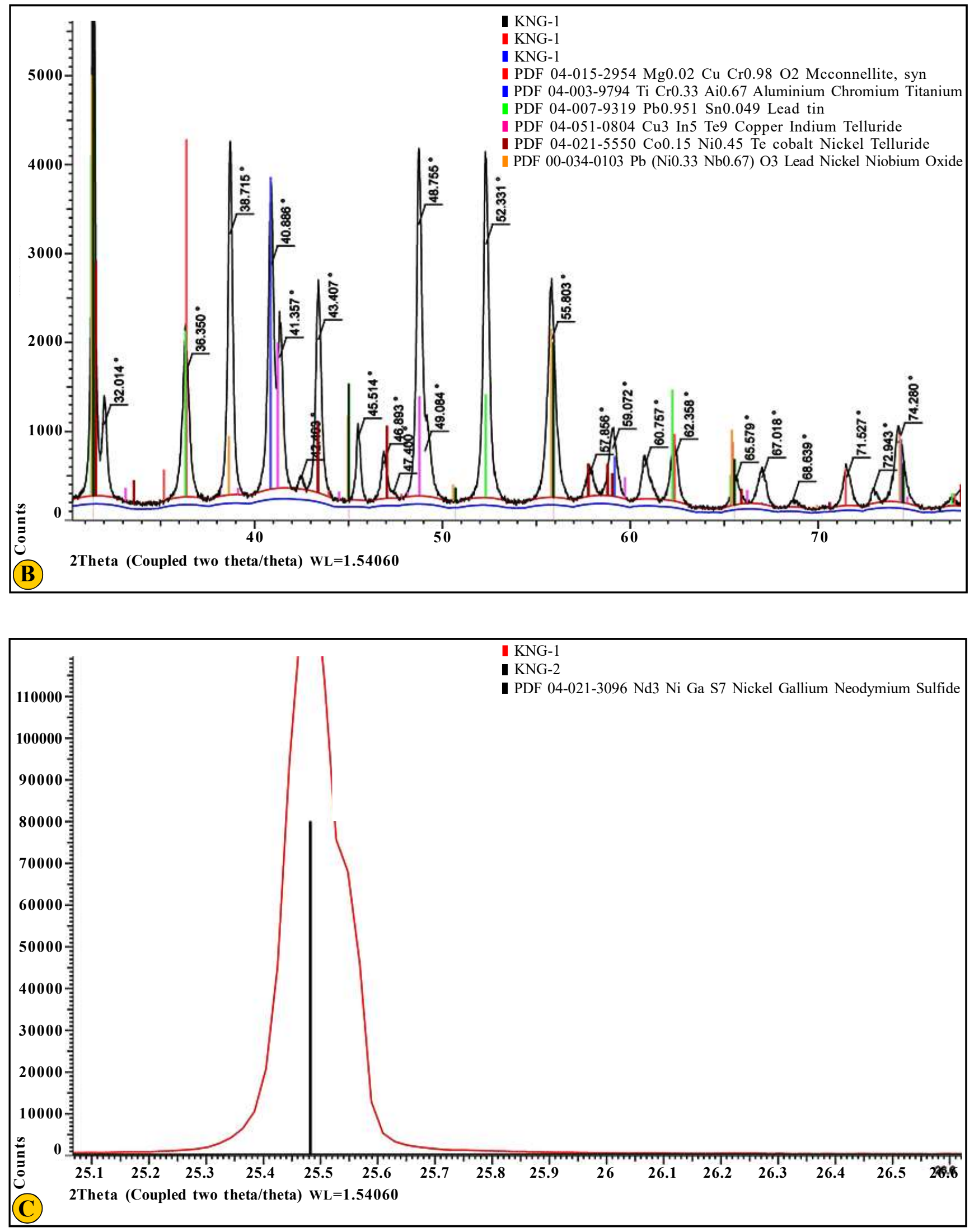

Figure 6: 2Theta_(Coupled two theta/theta) for KGF 1\&2 (B-C). 

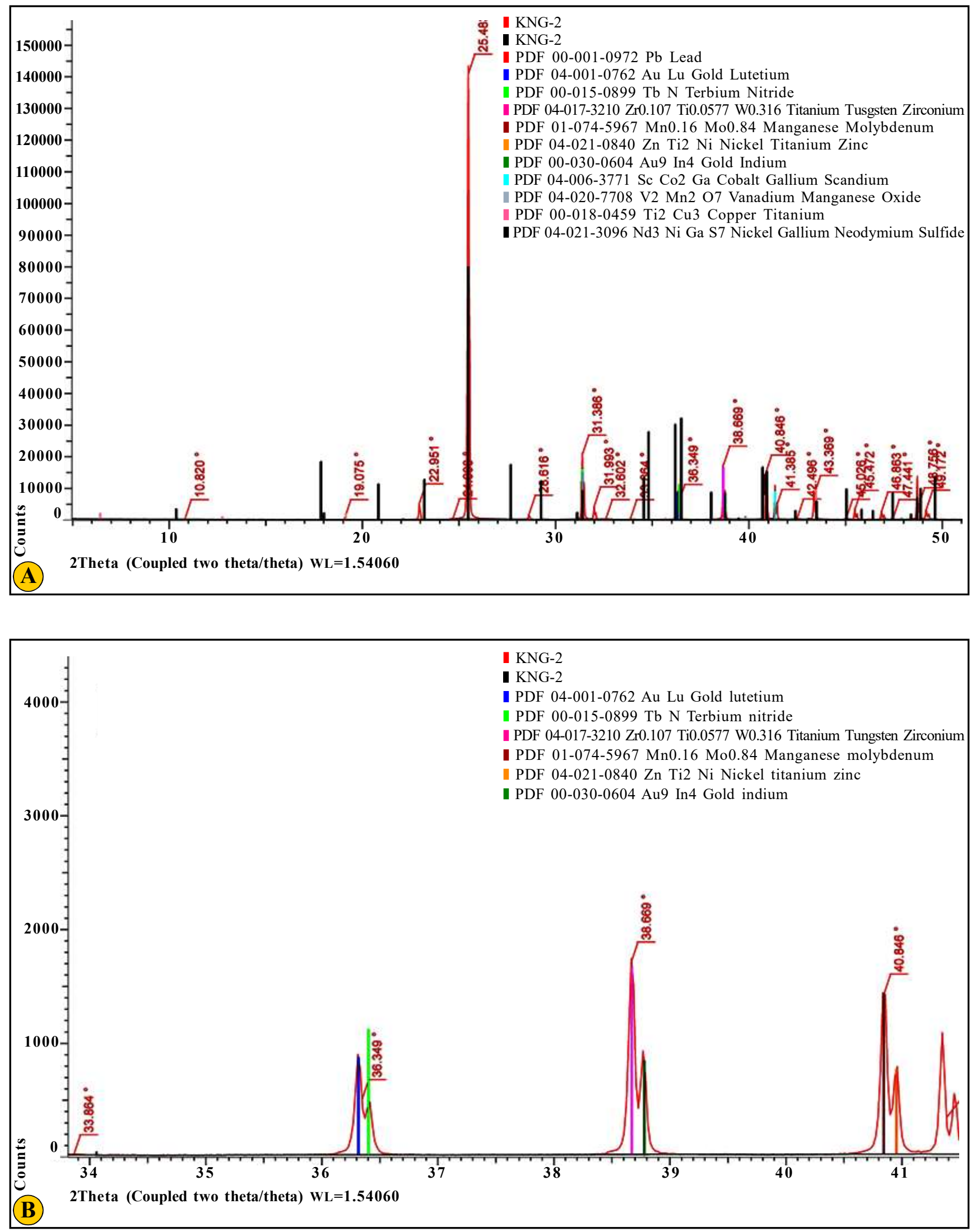

Figure 7: 2Theta_(Coupled two theta/theta) for KGF 2\&3 (A-B). 


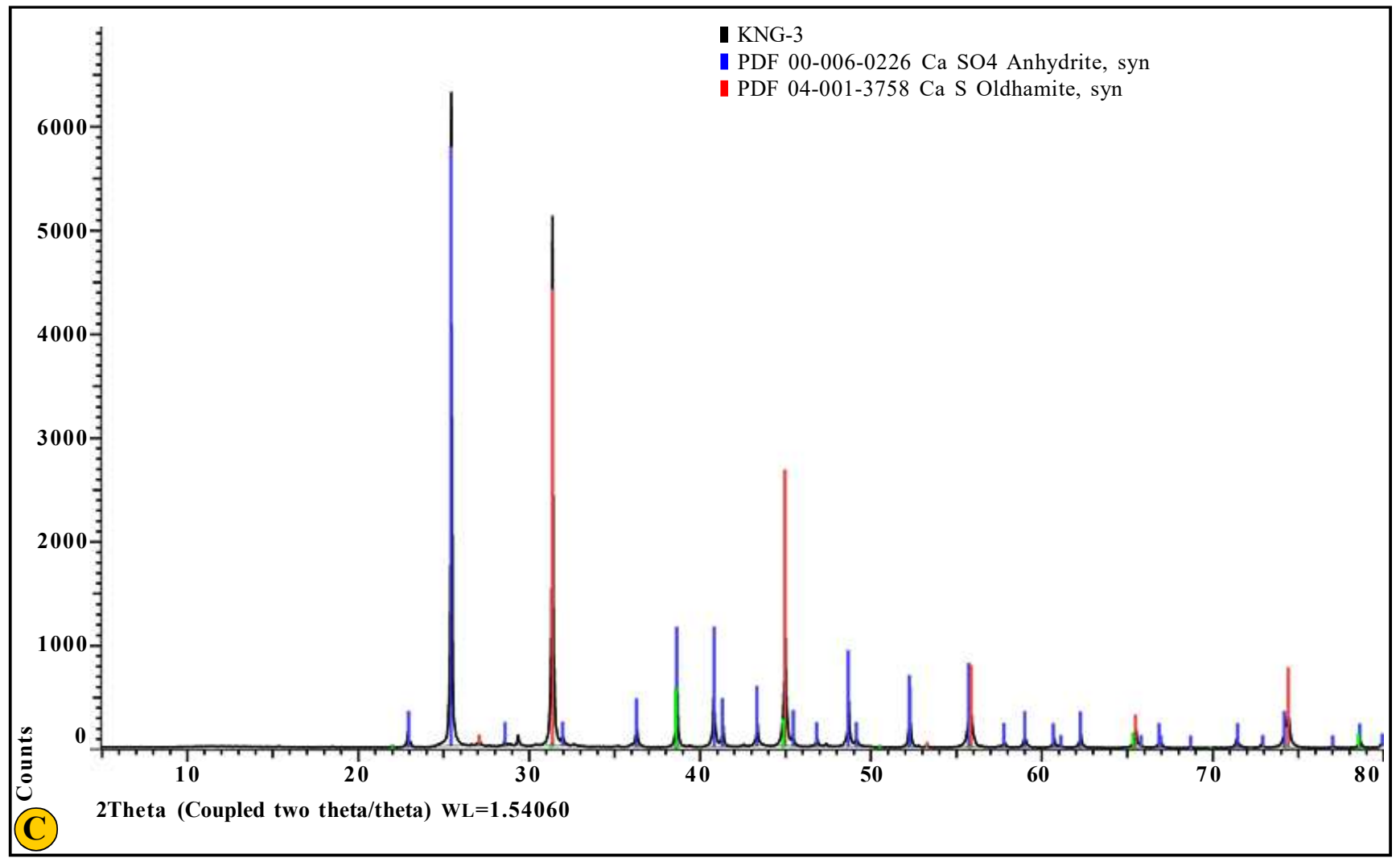

Figure 7: 2Theta_(Coupled two theta/theta) for KGF 2\&3 (C).

\section{Conclusion}

The Unani formulation, Kushtae Gaodanti was subjected to various parameters to develop the standard operating procedures such as physicochemical parameters which helps as a standard along with the other parameters like HPTLC analysis, metal analysis, XRD studies. Safety evaluation of drug such as heavy metal analysis, contamination analysis suggested that the drugs are safe and can be used in further studies such as pharmacological study, clinical study, etc. Modern technique of HPTLC fingerprint analysis was employed and it is an important study in standardization and facilitate in separation of compounds present through isolation for further studies. Consequently the Kushtae Gaodanti drug was brought up in its quality to set as a reference standard. The present study serves in the quality assurance of Kushtae Gaodanti in the Unani System of Medicine with standardized parameters. The development of AYUSH medicines or traditional or Unani system of medicines with respective to safety, efficacy and quality will help not only to preserve the traditional heritage but also in the rationalize use of natural herbal products in the healthcare. Further, studies in the direction to evaluate the therapeutic efficacy of KGF1 and KGF2 by conducting animal trials may be conducted and also to confirm the detoxification related change, pharmacological effects should be evaluated in vivo studies on scientific parameters.

\section{Acknowledgements}

The author conveys his sincere thanks to Director, CSIR-IICT for providing the necessary facilities and supporting concern staff during the course of study.

CSIR-IICT manuscript communication no. IICT/Pubs./2020/077

\section{Conflict of interest}

The authors declare that there are no conflicts of interest in the course of conducting the research. All the authors had final decision regarding the manuscript and decision to submit the findings for publication.

\section{References}

Ali, S. S. (1979). Unani adviae mufarada: NCPUL, New Delhi, pp:33-58.

Anonymous, (1986). Qarabadeen-e-Majeedi, All India Unani Tibbi Conference, New Delhi, pp:307

Anonymous, (2004). Standardization of single drugs of unani medicine, Government of India, CCRUM, Ministry of Health and Family Welfare, New Delhi, pp:9-14.

Anonymous, (2006). National formulary of unani medicine. Department of AYUSH, Ministry of Health and Family Welfare, Government of India, New Delhi, Part 1, pp:66-70.

Anonymous, (2007). The unani pharmacopoiea of India. Department of AYUSH, Ministry of Health and Family Welfare, Government of India; New Delhi, Part I, Vol I, pp:7-8.

Anonymous, (2008). National formulary of unani medicine. Government of India, Ministry of Health and Family Welfare, Department of Ayurveda, Yoga and Naturopathy, Unani, Siddha and Homoeopathy (AYUSH), New Delhi, Part V, pp:54.

Anonymous, (2009a). Sehat afza unani dawai poudey, CCRUM, New Delhi, pp:17

Anonymous, (2009b). The unani pharmacopoeia of India, Part-I, Vol. VI, Ministry of Health and Family welfare, Govt. of India, New Delhi, pp:119-135. 
Dubey, N.; Dubey, N.; Mehta, R. S.; Saluja, A. K. and Jain, D. K. (2008). Quality assessment of kushta-e-gaodanti: A traditional unani medicine. Asian J. Res. Chem., 1(1):46-50.

Gani, N. (1998). Khazain-ul-Advia. Idara kitabus shifa. New Delhi, pp:230-231.

Ibn Baitar (1999). Al Jamiul Mufaradat al Advia wal Agziya, Urdu translation, Vol. 3, CCRUM, New Delhi, pp:170-175.

Kabeeruddin, M. (2007). Makhzanul Mufradat. (Rep. edition). Idara Kitabus-Shifa, Delhi.

Khan, M. A. (2012). Muheet e Azam, CCRUM, New Delhi, pp:319-320.

Khan, M. Y.; Gupta, P.; Bihari, B. and Misra, A. (2012). Quality government assessment of a traditional unani medicine: Kushta-e-Goadanti. Res. Pharm., 2(6):11-17.

Kulkarni, R. R.; Patki, P. S., Jog, V. P., Gandage, S. G. and Patwardhan, B. (1991). Treatment of osteoarthritis with a herbomineral formulation: A double-blind, placebo-controlled, cross-over study, J. Ethnopharmacol., 33(1-2):91-95.

Mohammad, N. I.; Shamsi, S. and Rabee, K. (2016). Comparative elemental analysis of Kushtae Sadaf, a Unani formulation. Int. J. Green Pharm., 10(3):S145.

Nadkarni, A. K. (1976). The indian materia medica, Vol. II, Popular Prakashan, Bombay, pp:74.

Naikodi, M. A. R.; Waheed, M. A.; Shareef, M. A.; Ahmad, M. and Nagaiah, K. (2011). Standardization of the Unani drug-Myristica fragrans Houtt. (Javetri)-with modern analytical techniques. Pharm. Meth., 2(2):76-82.

Parwaiz, M. A. and Parveen, N. (2012). The text book of Unani Pharmacy (Ilmul Saidla). Roshan printer press, New Delhi, pp:51-59,64.

Pifferi, G.; Santoro, P. and Pedrani M. (1999). Quality and functionality of excipients. Farmaco, 54(1-2):1-14.

Raju, P. V. S. (2019). The morphology and metallurgical implications for extraction of platinum group minerals (PGM's) in Chromitite. J. Geol. Soc. India, 94:47-52.
Raju, P. V. S.; Hart, C. J. R. and Sangurmath P. (2016). LA-ICP-MS and potential for rare earth elements from hutti gold mines and fingerprinting ore deposits. Journal of African Earth Sciences, 114:220-227.

Rasheed, N. M. A.; Nagaiah, K. and Waheed, M. A. (2013). Recent analytical techniques in quality control of indigenous system of medicine. Ann. Phytomed., 2(1):44-58.

Rasheed, N. M. A.; Nagaiah, K.; Mehveen, A.; Rehana, A.; Waheed, M. A. and Shareef, M. A. (2012). Phytochemical evaluation and quantification of beta-sitosterol in geographical variation of Withania coagulans Dunal by HPTLC ananlysis. Ann. Phytomed., 1(2):14-22.

Rasheed, N. M. A.; Rehana, A.; Ahmed, M.; Husain, K.; Waheed, M. A.; Arfin, S. and Aminuddin (2014). Standardization and HPTLC fingerprinting of a unani compound formulation "Habb-e-Paan" with modern techniques. Hipp. J. Unani Med., 9(2):141-152.

Rasheed, N. M. A.; Srividya, G. S. and Nagaiah, K. (2017). HPTLC method development and quantification of curcumin content in different extracts rhizome of Curcuma longa L. Ann. Phytomed., 6(2):74-81.

Rohit, T.; Baghel, D. S. and Singh, S. (2017). Physicochemical screening of Godanti bhasma: An effort to pharmaceutical standardization. J. Pharm. Res., 11(7):887-894.

Shinde, V. M.; Dhalwal, K.; Potdar, M. and Mahadik, K. R. (2009). Application of quality control principles to herbal drugs. Int. J. Phytomed., 1:4-8.

Singh, S. and Soni, G. R. (2004). WHO expert committee on biological Standardization. Ind. J. Med. Res., 120:497-498.

Street, R. A., Stirk, W. A. and Staden J. V. (2008). South african traditional medicinal plant trade-challenges in regulating quality, safety and efficacy. J. Ethnopharmacol., 119(3):705-710.

Tariq, M., Chaudhary, S. S. and Imtiyaz, S. (2013). Introduction to Kushta: A herbo-mineral Unani formulation. J. Pharm. Sci. Innov., 2(1):14-17.

Zillurahman, (1985). Jadeed Unani Dawasazi, Kutubkhana darul uloom, Meerut, Nomani Press Delhi, pp:82-90,176.

Citation: Mohammed Zafar, Mohammed Abdul Rasheed Naikodi, Kommu Nagaiah and P.V. Sunder Raju (2020). Development of standard operating procedures and quality standards of Kushta Gaodanti with HPTLC fingerprinting and hyphenated techniques. Ann. Phytomed., 9(1):66-77. http://dx.doi.org/10.21276/ap.2020.9.1.8 